\title{
Mobile Technologies for Lifelong Learning
}

\author{
Alina-Mihaela ION \\ Department of Economic Informatics and Cybernetics \\ The Bucharest Academy of Economic Studies, Romania \\ alina.ion@ie.ase.ro
}

The article presents an analysis of the impact of using mobile devices on participants at the lifelong learning educational process. Human durable development involves adapting to new hardware and software technologies supported by the progress of information and communication technology. Along with technological evolution the access to mobile devices knew a significant growth and encouraged the extension of educational process towards lifelong learning through mobile devices. Thus m-Learning type of instruction for lifelong learning is strongly supported.

Keywords: Lifelong Learning, Computer Assisted Instruction, M-Learning, Mobile Devices, Information and Communication Technology

\section{1} Introduction

The progress known by the information and communications technology led to major changes in all spheres where it is used and, consequently in educational domain. Using technology in education encourages at the same time both traditional education process and lifelong learning.

Both at European level and worldwide there is an increasing attention given to lifelong educational process as a result of the awareness that sustaining lifelong learning process is in a direct relationship with the living standards of citizens and their quality of life. Investments in human capital support all other investments. This way, the importance of education and its role in society is emphasized.

\section{Extension of Traditional Education}

At European level, since 2002, m-Learning was seen as an extension of e-Learning. On this purpose, Ericsson implemented the project "From e-learning to m-learning" as part of the Leonardo da Vinci II program, under the coordination of the European Union.

According to [1], [2], Leonardo da Vinci II was an European vocational instruction program, representing a natural following of the Leonardo da Vinci I program, [3].

Leonardo da Vinci II program was conducted between January 2000 and December 2006, allowing the right of 31 European Union member states to participate at the competition, including Romania, which it was in the process of adherence at that time.

As [4] states, students in higher education are increasingly using mobile devices in their personal activities and also in their social activities, including their education.

According to [4], one of the most popular European applications as innovation is Federic@platform implemented at Federico II University of Naples, Italy. The platform provided to students is oriented to mLearning distance instruction type and can be accessed through a wide variety of smart phones and tablets. The applications provided by the Federal@ are: Federica WebLearning, FedericaMobile and Federica iTunes U.

Through these applications, the instructors have benefit from the necessary technology to create and customize educational materials, and students have access to information using a computer or a mobile device, as shown in Figure 1. 

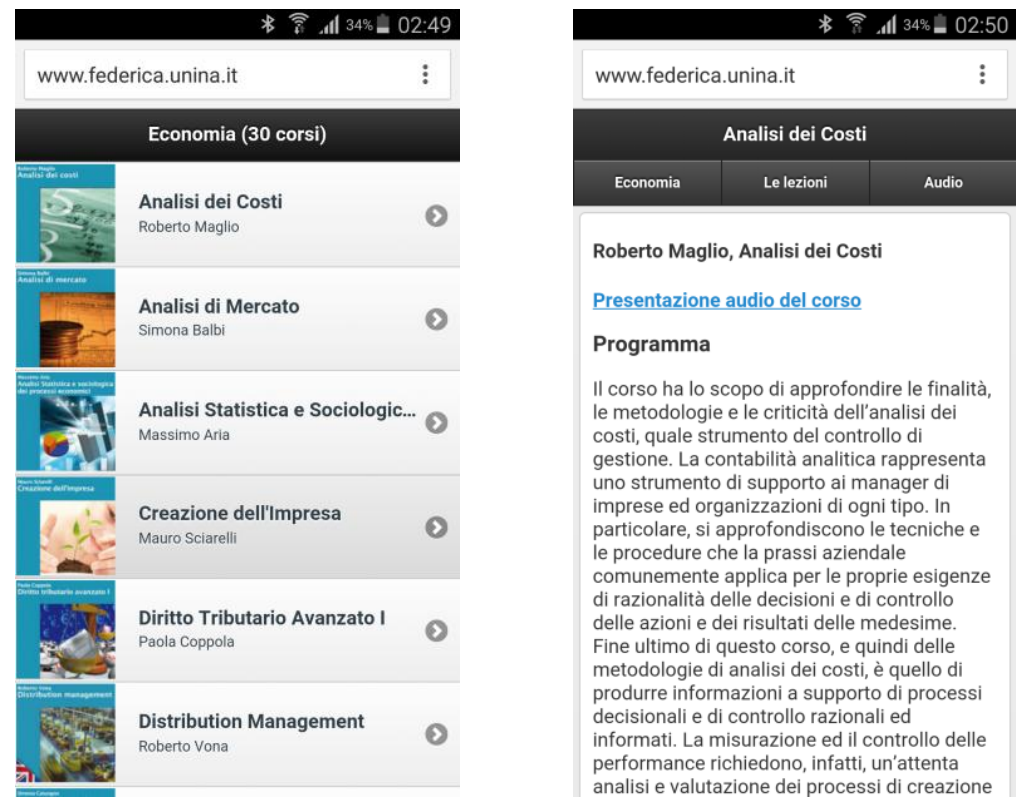

Fig. 1. Example of m-Learning courses for economics

Federico II University provides a wide variety of courses, corresponding to different specializations as Economics, Medicine, Pharmacy, Engineering, Philosophy, etc.

Generally, distance instruction using computers is considered to be an independent instruction. On the contrary, in the case of instruction through mobile devices, the educational process should be considered to be a complementary method for the classical education with presence in campus or even a complementary instruction method for distance learning.

The advantage provided by the small sizes of mobile devices allows them to be used at any time by those concerned to get documented in different areas. With a simple Internet connection, a charged battery and available time, users have the opportunity to study whether they are into a classroom, in transportation means or at home, completing this way their knowledge on their domain of interest. Such activities encourage lifelong learning towards a sustainable human development.

Mobile devices are mainly used for communicating via short text messages, searching of information or displaying media content. According to [5], materials involving writing large size texts are not supported due to the small size of the screen which makes them difficult to be read. In order not to complicate the process of reading and not to get the student tired, educational supports for m-Learning must fulfil a certain standard and must be designed right from the start for small screens. Displaying contents optimally on the screens of mobile devices and structuring them accordingly will increase the interest of students towards m-Learning.

The communication in educational process is encouraged by the mobile technologies. Those who use m-Learning specific applications can communicate verbally or in writing, can collaborate through shared applications and can interact through the Social Media specific applications.

Communication facilities through SMS, dialog and chat encourage collaborative activities between those who study using these methods. In [5], based on the arguments presented by [6], the idea according to which mobile devices represent collaborative learning method.is sustained.

\section{M-Learning and Sustainable Human Development}

Mobile devices provide support especially for fast communication. Mobile devices have the main role of providing support for achieving synchronous and asynchronous communication between users, according to 
[7]. The development of social aspects of the users is such encouraged.

[8] highlights the functionalities of a mobile phone, based on a survey conducted among students. Analysis of their responses resulted in a ranking of the functionalities of mobile phones used in the educational process, as follows:

1. Communication

2. Accessing educational content

3. Accessing useful information

4. Social Networking

\section{Content authoring}

The functionalities mentioned above, which are specific to mobile phones, can be extended as well to other mobile devices such as laptops (considered to be partial mobile device) and tablets.

If from educational perspective, the utility of mobile devices is represented by the order of functionalities above from 2 to 5, Figure 2, when we have a general look, the importance of the functionalities is exactly the reverse order, from 5 to 2 .

Over-advanced functionalities

Advanced functionalities

Basic functionalities

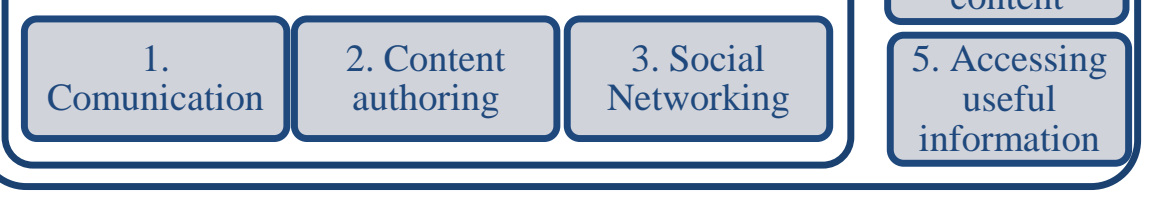

6. Accessing

educational

content

5. Accessing

useful

information

Fig. 2. The functionalities of mobile devices

Therewith, the functionality of mobile devices can be grouped into:

- Basic functionalities represented by communication (verbal communication, SMS, e-mail), content authoring (texts composition, pictures taking, audiovideo recording, audio recording) and social networking (creating and publishing content on Facebook, Twitter, YouTube, Instagram, Pinterest).

- Advanced functionalities, represented by the possibility to access useful information (on websites such as electronic dictionaries, blogs specialized in a particular area) and accessing the educational content available via PDF files, web pages, and interactive applications.

Some users of the advanced functionalities of mobile devices are aware of the importance of getting documented in a particular field, clarifying certain concepts or terms used casually in a particular context. Unwittingly, they will use these advanced functionalities provided by mobile devices for self-training. In this case, the educational process is almost imperceptible to the user. Such self-training activities can be carried out by users of all ages, regardless of their training. The activity itself can be considered to be specific to lifelong learning, voluntary, without the user of the device to specifically be aware of the educational process.

The awareness generally occurs among users actively involved in the educational process. This category of users of mobile devices represents a particular case of all users conducting intentional learning and organized learning, activities specific to lifelong learning. A distinction between these two concepts is made in [9].

The definition of these concepts can be adapted for the users of mobile devices in education. 
For the users of mobile devices, considering [9] we can say that intentional learning represents the fact that, at a certain moment of time after completing the initial formation, the user becomes aware about the continuation of his education in a certain domain and by the importance of participating at further formation courses in order to increase his level of knowledge, competencies and skills in the domain of activity he is interested in.

In this scenario, the use of functionalities provided by mobile devices for searching educational materials, enrolling and graduating specialty or forming courses represents operations that the user conducted intentionally and is aware of.

Compared to intentional learning, from the perspective of lifelong learning and particularizing for the case where mobile devices are used in the educational process, organized learning represents learning that has been planned in a program. The participants do not express explicitly their intention to follow such type of learning but rather they generally choose this following some constraints at work.

Implicitly, the users of advanced functionalities, both those who are aware of the educational process and those which are self-instructing, use also the basic functionalities provided by mobile devices.

Along with the raise of his instruction level, the user will be capable of using high level software technologies in order to develop educational content. Thus, Figure 2 can be improved by adding the sixth functionality represented by the use of high level technologies.

The use of mobile devices in education must be seen further as a complementary instruction method. As an instructor choses to present the content of the same course either in a classical way, using a PDF file, or in an interactive way, using specific software technologies, both of these methods being used to train, mobile technologies can also be viewed as an alternative way of training. In order to learn, a student may choose to access educational materials either on a computer or on a mobile device, be it a smartphone. The objective of the instruction and the role of the device remain the same.

Even if it should not matter how the user choses to view the information in a completion test of an organized course (PDF or interactive), when talking about mobile devices the situation is different. Mobile devices may be used for routine evaluation but, for the moment, the final evaluation conducted exclusively on mobile phone or tablet is not possible.

In order to get a correct and fair assessment, all those taking an exam at the same time should have exactly the same type of device or devices with identical performances. The problems that arise not allowing the completion of an educational process by giving final tests on the mobile phones or tablets can be divided into two categories: financial problems and methodological issues. From the financial point of view, investments should be made in laboratories in order to provide students with access to all types of mobile devices that they can use along the educational process for studying and also for getting familiar with. Thus, in the event of taking a test on such a device, the user should have the necessary skills to use the device without any problems.

From the methodological point of view, the problems that may occur are caused by the novelty of the use of mobile devices in an educational process that is finalized through awarding recognized diplomas. There should be different methodologies developed for creating educational content to be proposed in the training process.

\section{M-Learning and Lifelong Learning}

In order to encourage study outside seminars and lectures, the students of the Faculty of Business Administration taught in French may use for the IT disciplines an educational platform whose interface was adapted for mobile devices, www.it.ase.ro/fr .

Students targeted by the platform belong to the age group 18 - 24. People in this age interval are particularly interested in using information and communication technology and hence in using mobile devices. These 
devices are used in current activities and, directly, in educational activities also.

As information and communication technology evolves, the www.it.ase.ro/fr platform was optimized in order to allow the educational process to be also conducted on mobile devices. The decision to encourage lifelong learning through mobile devices was taken based on statistics recorded on the user access on www.it.ase.ro/fr, Figure 3.

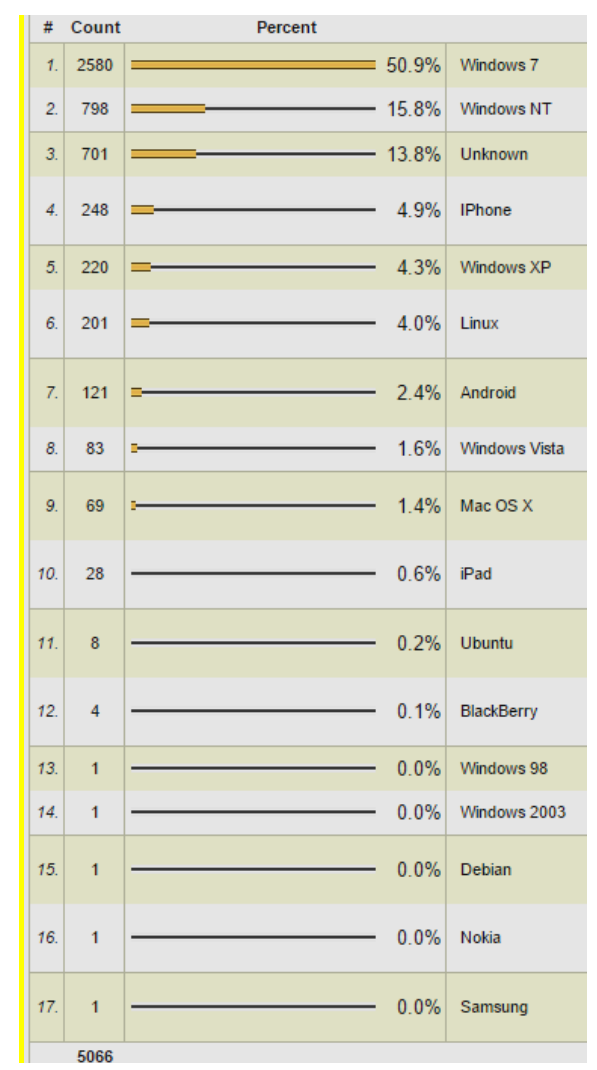

Fig. 3. Visits on www.it.ase.ro/fr platform in January 2015

Of the 5066 visits on the platform in January 2015 , approximately $8 \%$ were done using a mobile device such a tablet or a mobile phone, Figure 4.

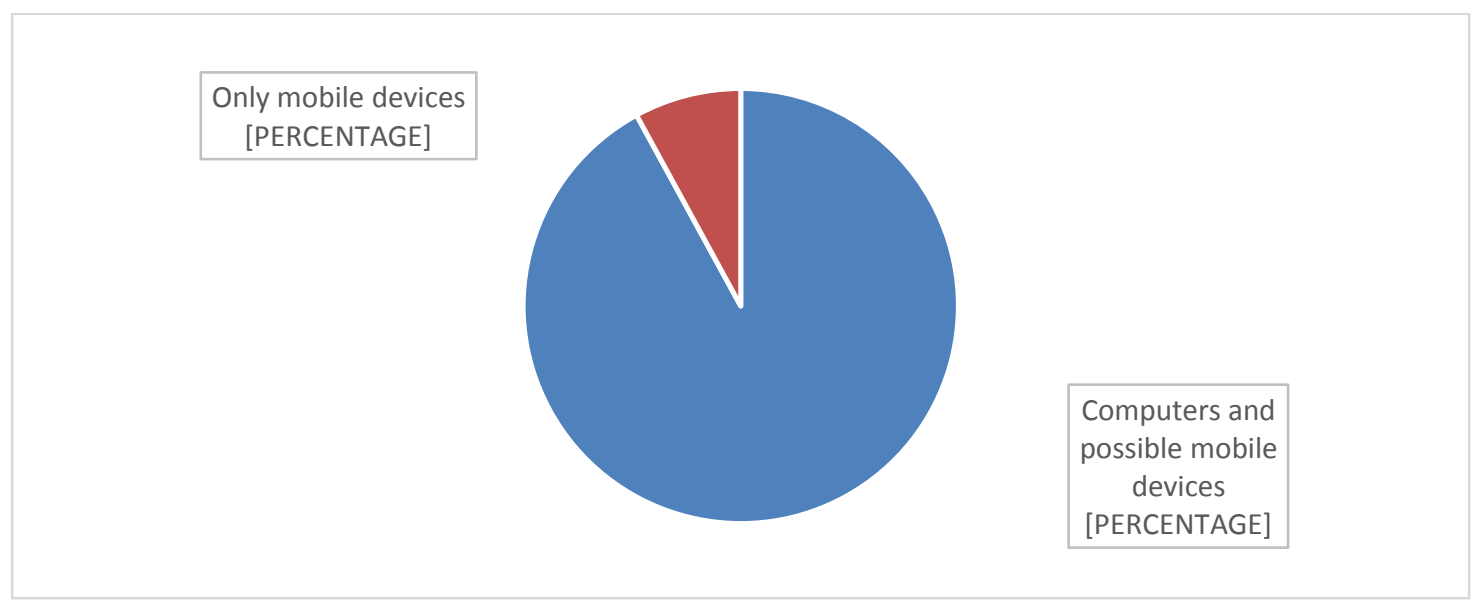

Fig. 4. The use of mobile devices in education

Considering that some of the operating systems on devices accessing www.it.ase.ro/fr could not be identified on about $13 \%$ of total visits and that for mobile devices (tablets and phones) using Windows operating system there was no distinction made, the percent of approximately $8 \%$ visits from mobile devices is a minimum one and definitely is higher in reality, Table 1. 
Table 1. www.it.ase.ro/fr visits by type of device

\begin{tabular}{|c|c|c|c|}
\hline $\begin{array}{l}\text { Visits - physical } \\
\text { number of users }\end{array}$ & $\begin{array}{c}\text { Visits - } \\
\text { percentage } \\
\text { values }\end{array}$ & Identified OS & Category of device \\
\hline 2580 & $50,928 \%$ & Windows 7 & computer \\
\hline 798 & $15,752 \%$ & Windows NT & computer \\
\hline 701 & $13,837 \%$ & Unknown & computer \\
\hline 220 & $4,343 \%$ & Windows XP & computer \\
\hline 201 & $3,968 \%$ & Linux & computer \\
\hline 83 & $1,638 \%$ & Windows Vista & computer \\
\hline 69 & $1,362 \%$ & Mac OS X & computer \\
\hline 8 & $0,158 \%$ & Ubuntu & computer \\
\hline 1 & $0,020 \%$ & Windows 98 & computer \\
\hline 1 & $0,020 \%$ & Windows 2003 & computer \\
\hline 1 & $0,020 \%$ & Debian & computer \\
\hline 4663 & $92,045 \%$ & & Total computers \\
\hline 248 & $4,895 \%$ & IPhone & mobile device \\
\hline 121 & $2,388 \%$ & Android & mobile device \\
\hline 28 & $0,553 \%$ & $\mathrm{iPad}$ & mobile device \\
\hline 4 & $0,079 \%$ & BlackBerry & mobile device \\
\hline 1 & $0,020 \%$ & Nokia & mobile device \\
\hline 1 & $0,020 \%$ & Samsung & mobile device \\
\hline 403 & $7,955 \%$ & & Total mobile devices \\
\hline 5066 & $100,000 \%$ & & Total \\
\hline
\end{tabular}

Given such conditions, the interest of students in using exclusively mobile devices to access educational materials supports the development of the platform towards an mLearning platform.

Currently there is no methodology to quantify the knowledge acquired by students as a result of using mobile devices on educational purposes. This knowledge is embedded in the final grade that the student gets on his final assessment traditionally held in the classroom.

Students using mobile technologies on educational purposes outside seminars and lectures deploy activities that are specific to lifelong learning. As there is no universally recognized methodology or standard in $\mathrm{m}$ Learning, instructors, tutors and professors that create educational content for mobile devices generally apply the pedagogical principles specific to traditional learning or distance learning activities.

According to [10] educational materials created specifically for mobile devices are designed to not request the attention of the user for one activity for more than a few minutes. Also, a simplified navigation through educational materials and the optimization of content for all screen sizes is recommended.

If pedagogical concepts are applied in the process of creating educational concepts for the students involved in activities specific to lifelong learning, then andragogic principles should be considered when creating educational content for adults. Thus, instruction methods must be differentiated when applied to students or adults, according to pedagogical principles that correspond to children and youth education and to 
andragogic principles corresponding to adult education, as stated in [11].

According to [9] lifelong learning has the role to increase the levels of previously acquired knowledge, abilities and competencies for a person, generally being an adult. This type of education can be defined as a self-instruction form. In terms of trigger factor that determines educational activities specific to lifelong learning regarded as self-instruction, there are two types of learning that can be conducted: intentional learning and organized learning, conform Figure 5.

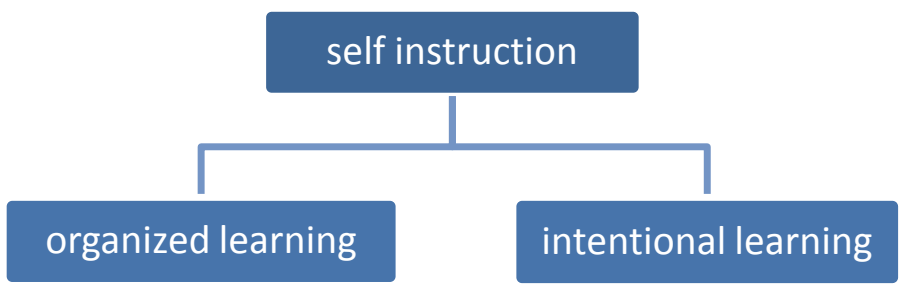

Fig. 5. Types of self-instruction

Adults engaged in lifelong learning activities for professional reconversion, specialization in a certain field or as requested at the workplace, behave slightly different than students. Using mobile devices in order to encourage lifelong learning for adults must be correlated with their previous training and with their abilities in using the new technologies of information and communication.

Intentional learning, according to [9] is defined as the option of a person taken, generally, after completing the initial formation, when he acknowledges the importance of getting specialized in a certain field as part of his professional or personal evolution. Unlike intentional learning, organized learning is conducted inside a program and the participants are forced by circumstances to take part. This type of learning is usually organized for employees at the employers' request. In order to encourage permanent instruction and study, using mobile devices may be a solution.

\section{Conclusions and Future Directions}

The programs proposed and sustained at European level in the past 25 years represent the proof of the interest shown for transforming Europe into a competitive and dynamic knowledge-based economy, as its development is intended to be a durable and sustainable one. Such a development can only be achieved through investments in human capital, raising its educational level. Within the European Union, one priority for the coming years is to create programs that allow sustainable development of EU citizens.

Including mobile devices in educational activities provides more support to students. Still, this should be seen as an activity that is complementary to the process of lifelong learning, which is traditionally achieved by presence on campus, or through personal computers.

The advantages of accessing educational content on the tablet or mobile phone are similar to those of accessing the contents from the personal computer. Deploying complex activities which involve the use of over-advanced functionalities of mobile devices is hampered by the small size of the screen.

The basic functionalities of mobile devices are represented by rapid communication and information transmission, two activities that support collaborative activities between students or between common users of applications specific to educational field. Using mobile devices in everyday activities directly encourage voluntary or organized involvement in educational activities. Due to the advantage of having the ability to keep 
the user in constant contact with the educational or lucrative activities he conducts, the use of mobile devices encourages lifelong learning process.

\section{Acknowledgment}

This paper was co-financed from the European Social Fund, through the Sectorial Operational Programme Human Resources Development 2007-2013, project number POSDRU/159/1.5/S/138907, "Excellence in scientific interdisciplinary research, doctoral and postdoctoral, in the economic, social and medical fields - EXCELIS", coordinator The Bucharest University of Economic Studies, Romania.

A shorter version of this paper was presented at the 14th International Conference on Informatics in Economy (IE 2015), May 1-3, 2015.

\section{References}

[1] P. Landers, "From e-Learning to mLearning," 08 2002. [Online]. Available: http://learning.ericsson.net/mlearning2/pr oject_one/leo.html. [Accessed 03 2015].

[2] CE, „Obiectivele Europa 2020,” 1002 2014. [Interactiv]. Available: http://ec.europa.eu/europe2020/europe2020-in-a-nutshell/targets/index_ro.htm. [Accesat 0412 2014].

[3] UE, Educaţie şi formare: cadru general Programul de învăţare pe tot parcursul vieţii 2007-2013, 2009.

[4] eprof.ro, "Tehnologii Mobile în Învățare," 2015. [Online]. Available: http://www.eprof.ro/doc/Mobile_learning .pdf.
[5] A.-M. Ion și P. Pocatilu, „Using MLearning in Education," în The Proceedings of the 11th International Conference on Informatics in Economy, Bucureşti, 2012.

[6] H. Uzunboylu, N. Cavus și E. Ercag, „Using mobile learning to increase environmental awareness," Computers \& Education, vol. 52, nr. 2, pp. 381-389, february 2009.

[7] A.-M. Ion și D. Vespan, „Collaborative Learning and Knowledge Transfer in Consciousness Society," Informatica Economica, vol. 15, nr. 3, pp. 115-127, 2011.

[8] L. Nielsen, " Research-based proof that students use cell phones for LEARNING," 16 February 2013. [Online]. Available: http://theinnovativeeducator.blogspot.co.a t/2013/02/finally-research-based-proofthat.html. [Accessed 2015].

[9] A.-M. Ion, "Lifelong Learning and Human Sustainable Development in European Union," in Proceedings of the 9th International Conference On Economic Cybernetic Analysis: Positive And Negative Effects Of European Union And Eurozone Enlargement Pone-2014, Oct 31 - Nov 1st 2014, Bucharest, 2014.

[10] EDUCAUSE, "Mobile Apps for Learning," 2010.

[11] N. Slavkovic and A. Savic, "The Usage of m-learning for adult education in Serbia," Procedia-Social and Behavioral Science, no. 174, pp. 2806-2812, 2015.

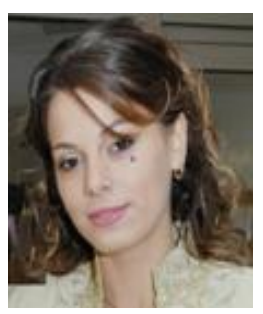

Alina-Mihaela ION graduated the Faculty of Cybernetics, Statistics and Economic Informatics at the Bucharest University of Economic Studies. She has a master in Informatics Project Management and a $\mathrm{PhD}$ in Economic Informatics from the Academy of Economic Studies. She is certified as IPMA level D in Project Management by Romanian Project Management Association. Her activity and research focus on e-Learning, assisted instruction, collaborative platforms and Internet Technologies. 